\title{
El mundo nuevo imaginado por Louise Michel. Literatura, labor editorial y utopía anarquista
}

The new world imagined by Louise Michel. Literature, editorial work and anarchist utopia

María MiguelÁÑEZ MARTíneZ

Universidad Carlos III de Madrid

\section{RESUMEN}

Este artículo examina las novelas de Louise Michel Les Microbes humains (1886), Le Monde nouveau (1888) y Le Claque-dents (1890) y sus posteriores reediciones. Ahonda en el papel de la militante como escritora anarquista, más concretamente, como creadora de mundos utópicos, claramente ideologizados, así como en las redes editoriales anarquistas y no anarquistas que le dieron o negaron difusión y los motivos de estas inclusiones y exclusiones. Estas tramas de impresión y de traducción son analizadas desde un enfoque transnacional.

\section{PALABRAS CLAVE}

Louise Michel; anarquismo; literatura; edición; utopía; género.

\section{ABSTRACT}

This article examines Louise Michel's novels Les Microbes humains (1886), Le Monde nouveau (1888) and Le Claque-dents (1890) and their subsequent reprints. It delves into the role of this militant as an anarchist writer, more specifically, as a creator of utopian worlds. It studies the publishing networks, anarchist and non-anarchist, that gave or denied her circulation and the reasons why these inclusions or exclusions took place. These publishing and translations decisions are analysed from a transnational approach.

\section{KEYWORDS}

Louise Michel; Anarchism; Literature; Edition; Utopia; Gender. 
A finales de la década de 1880, la editorial parisina Dentu publicó un ciclo de tres novelas escritas por Louise Michel. Les Microbes humains (1886), Le Monde nouveau (1888) y Le Claque-dents (1890) forman parte de un momento muy activo de su producción literaria ${ }^{1}$. Aunque la anarquista francesa había sido una autora prolífica, esta trilogía tiene la particularidad de haber sido redactada en solitario. Todas sus incursiones anteriores en el género novelístico, al menos las que habían sido editadas en formato libro, habían sido realizadas en coautoría. Hasta hace muy poco, el acceso a este corpus se hacía de forma necesariamente fragmentaria, por múltiples motivos, como se verá más adelante. Recientemente, la edición que la editorial de la Universidad de Lyon ha hecho del conjunto, con introducción crítica y muy enjundiosa de los historiadores de la literatura Claude Rétat y Stéphane Zékian, ha facilitado su recuperación y lectura ${ }^{2}$.

Este artículo tiene como objetivo la inclusión de esta trilogía en algunas discusiones recientes de la historiografía anarquista y de la historiografía social y cultural de la escritura, la traducción y la edición, puesto que ambas ramas de la investigación histórica se enriquecen mutuamente debido a los enormes vasos comunicantes que se tejieron entre la propaganda anarquista y las prácticas lectoras y editoras desde finales del siglo XIX hasta hoy en día. Estos cruces ameritan, todavía, diferentes aproximaciones, vinculadas, en buena medida, al estudio de la circulación transnacional de ideas, personas y artefactos culturales. Atender a estas novelas nos devuelve, además, un reflejo más preciso de algunas de las caras menos conocidas del complejo poliedro que fue Louise Michel como militante anarquista. La activista y escritora ha sido objeto de una profunda renovación historiográfica en las últimas décadas, al calor del centenario de su muerte (2005), pero sobre todo a raíz de la conmemoración de la Comuna de París, durante las cinco décadas que separan el centenario y el sesquicentenario de aquella primavera revolucionaria (1971-2021). Sin duda, 1871 es el aquí y el ahora con el que más se ha vinculado, por momentos encadenado, a Louise Michel, la communarde.

Sidonie Verhaegue ha trazado muy bien los procesos simbólicos al interior de la memoria colectiva nacional francesa que han impulsado las diferentes apropiaciones de la figura de Louise Michel $^{3}$. Para esta autora, Louise Michel ha seguido una "carrera simbólica” bien delimitada, aunque siempre disputada y conflictiva. Se convirtió en un símbolo, primero, para la memoria comunista; después lo fue del feminismo de la segunda ola y, en los últimos años, del feminismo de la diferencia y su teorización de pautas de escritura propiamente femeninas. Recientemente, mediando estos tres procesos, Louise Michel se ha integrado en el panteón de las mujeres y los hombres ilustres de la memoria republicana. Su admisión como figura relevante de la historia nacional francesa finalmente invierte una exclusión inicial y muy duradera que se

1. Louise Michel, Les Microbes humains, París, Dentu, 1886; Louise Michel, Le Monde nouveau, París, Dentu, 1888; Louise Michel, Le Claque-dents, París, Dentu, [1890].

2. Claude RÉTAT y Stéphane ZÉKiAn, "Présentation”, en Louise Michel, Trois Romans. Les Microbes humains. Le Monde nouveau. Le Claque-dents, Lyon, Presses universitaires de Lyon, 2013, pp. 9-51. Salvo que se indique lo contrario, las referencias a estas tres novelas se realizan según esta versión. Opto por traducir al castellano este texto y el resto de las citas directas que se hacen en este artículo.

3. Sidonie Verhaeghe, Vive Louise Michel! Célebrité et postérité d'une figure anarchiste, Vulaines-surSeine, Éditions du Croquant, 2021. 
remonta a los tiempos de la Tercera República francesa y su lucha contra el anarquismo ${ }^{4}$.

Estos procesos memorialísticos han oscurecido, sin embargo, la dimensión teórica y política de la militancia y la escritura de Louise Michel. Al menos, no los han trazado suficientemente, quedando velados bajo ideologemas bien conocidos como el de la Pétroleuse, la Virgen Roja o la Buena Luisa, tan sacrificada y bondadosamente romántica ${ }^{5}$. Autoras como Claire Auzias, Constance Bantman y Sidonie Verhaegue han abierto el camino de un análisis más profundo de esa matriz ideológica, aprehensible a partir de sus formas de militancia y de escritura, y no tanto de sus obras teóricas, que en el caso de Louise Michel apenas existieron ${ }^{6}$. En este sentido, este artículo se propone aportar algo sobre Louise Michel como escritora anarquista, más concretamente como creadora de mundos utópicos, claramente ideologizados, así como sobre las redes editoriales anarquistas y no anarquistas que le dieron o impidieron difusión y los motivos de estas inclusiones y exclusiones.

\section{La escritura de Louise Michel entre 1886 y 1890}

Louise Michel (1830-1905) tenía cincuenta y seis años cuando se publicó la primera parte de la trilogía Dentu, Les Microbes humains. Su madre, tan importante en su vida, había fallecido recientemente, al igual que su ídolo Victor Hugo. Aunque físicamente muy envejecida, tras años de miseria y de prisión, los escritos del yo de la autora, su correspondencia y su autobiografía, que también han sido recientemente editados, la muestran, sin embargo, políticamente muy activa. Por aquel entonces, Michel estaba también fuertemente involucrada en sacar adelante un ciclo de escritura revolucionario propio (escrito “por ella misma”) que bien podría consagrarla como autora de novelas, pese a los insistentes rechazos de la crítica ${ }^{7}$.

4. Véanse los aledaños históricos de las Leyes execrables contra el anarquismo que acompañaron el ciclo de atentados de los años noventa del siglo XIX en Francia: Jean MAITRON, Le mouvement anarchiste en France, vol. 1, Des origines à 1915, París, Gallimard, 1992 ( $\left.1^{\mathrm{a}} 1951\right)$; Vivien BouHEY, Les anarchistes contra la République. Contribution à l'histoire des réseaux sous la IIle République (1880-1914), Rennes, Presses Universitaires de Rennes, 2008; John MERRIMAN, El club de la dinamita. Cómo una bomba en el París fin de siècle fue el detonante de la era del terrorismo moderno, Madrid, siglo XXI, 2020 (1ª 2009).

5. Algunas de las obras canónicas: Edith ThomAs, Louise Michel, Montreal, Black Rose Books, 2009 (1 ${ }^{\text {a }}$ 1971); Anne SizArre, Louise Michel, L'absolu de la générosité, París, Desclée de Brouwer, 1995; Paule LeJeune, Louise Michel. L’indomptable, París, L'Harmattan, 2002; Joel DAUPHINÉ, La Déportation de Louise Michel: vérité et légendes, París, Les Indes savantes, 2006.

6. Sidonie VerhaEghe ha señalado la ausencia de obra teórica de Louise Michel como uno de los motivos de la escasa profundización en su dimension teórico-política en "Une pensée politique de la Commune: Louise Michel à travers ses conferences”, Actuel Marx, 66 (2019), pp. 81-98, https://doi.org/10.3917/amx.066.0081, e ídem, “Louise Michel, une théoricienne anarchiste”, en Louise MiChel, La Commune, París, Éditions du Détour, 2020, pp. 3-17. Claire AuziAs, Louise Michel, une anarchiste hétérogène, París, Éditions du Monde Libertaire, 1999; Constance BANTMAN, "Louise Michel's London years: A political reasssessment (1890-1905)”, Women's History Review, 26/6 (2017), pp. 994-1012, https://doi.org/10.1080/09612025.2017.1294393.

7. El primer volumen de sus memorias portaba ese subtítulo de “escritas por ella misma” (Xavière GAUTHIER (ed.), Je vous écris de ma nuit: correspondance générale de Louise Michel, 1850-1904, París, Editions de Paris, 1999). La autobiografía a la que nos referimos es Louise MiCHEL, À travers la mort. Mémoires inédits, 1886-1890, París, La Découverte, 2015, en su edición crítica realizada por Claude RÉTAT y acompañada de un dossier documental. Para Louise MiCHEL, publicar sus memorias fue un proceso complejo y fragmentario. El primer volumen apareció el mismo año del tomo inaugural de la 
Las tres novelas se inscriben en un periodo muy fértil de su literatura ${ }^{8}$. Entre 1886 y 1890 vieron la luz relatos en primera persona, obras de teatro, recopilaciones de poemas, narraciones cortas, escritos científicos y pequeños folletos de elaboración teórica anarquista firmados por Louise Michel $^{9}$. Resulta llamativo si lo comparamos con su producción literaria hasta entonces, concentrada en sus veinte años anteriores (18661886) y basada en cuentos, algún folleto y, sobre todo, novelas en coautoría ${ }^{10}$. La que podría haber sido su primera novela escrita en solitario, Le Coq rouge, en 1882, había quedado inacabada ${ }^{11}$. El período escritural de 1886 a 1890 también resulta llamativo si lo comparamos con el periodo posterior y final de su vida (1890-1905). En 1894, con Louise Michel instalada en Inglaterra, se reeditó y completó su obra poética, À travers la vie, con el mismo título que en $1888^{12}$. Finalmente, en 1898 , se imprimió la que sería su obra más conocida y más veces reeditada desde entonces hasta hoy, su relato sobre la revolución parisina de marzo de 1871: La Commune $(1898)^{13}$. Muchas de sus obras, sin embargo, se perdieron, algo que ella lamentó constantemente en sus escritos. La actual labor de edición de la obra completa micheliana no deja de sacar a la luz nuevos

trilogía Dentu, 1886: Louise Michel, Mémoires de Louise Michel, écrits par elle-même, París, F. Roy, 1886. El segundo volumen, que apareció en la prensa en formato folletín en 1890 y que se había perdido, es el editado por La Découverte en 2015. Louise MiCHEL elaboró, posteriormente, en Londres, una segunda versión de esta segunda parte de sus memorias, editada en el año 2000: Louise Michel, Histoire de ma vie, Seconde et troisième parties, Londres 1904, Lyon, Presses universitaires de Lyon, 2000 (texto editado y presentado por la escritora y académica Xavière GAUTHIER) que es también interesante para el periodo estudiado aquí. Existen otros relatos autobiográficos de Louise MICHEL.

8. RÉTAT y ZÉKIAN, “Présentation”, p. 9.

9. Relatos en primera persona: Mémoires de Louise Michel; "Mémoires de Louise Michel, 'volumen second'”, L'Égalité, Organe de concentration socialiste, 1890. Obras de teatro: Le Coq Rouge, París, Edinger, 1888; La Grève, s.l., s.n., 1890. Libros de poesías: À travers la vie, París, Librairie des publications à cinq centimes, [1888]. Relatos cortos: L'Ėre nouvelle, Pensé dernière, souvenirs de Calédonie (chant des captifs), París, Librairie socialista international, Achille Le Roy, 1887; Les Crimes de l'époque, [París], [Blanpain], [1888]. Escritos científicos: Lectures encyclopédiques par cycles attractifs, París, Librairie d'éducation laîque, 1888. Folletos de elaboración teórica: Prise de possession, Saint-Denis, Publication du Groupe anarchiste de Saint-Denis (La Jeunesse libertaire), 1890. Se reedita también Contes et légendes, París, Kéva,1887 (1ª ed.: París, Kéva, 1884).

10. Novelas en coautoría: Louise MiCHEL y Marguerite Victoire TinAYRE, La Misère, París, s.n., 1882; ídem e ídem, Les Méprisées, París, s.n., [1882], aunque MichEL negó haberla escrito; Louise MicHEL y Émile Gautier, Les Paysans, París, A. Carbillet, [1881]; Louise MiCHEL y Adolphe GriPPA, La Fille du peuple, s.l., s.n., [1883]; Louise MiCHEL y Jean WINTER, Le Bâtard impérial, París, Librairie nationale, 1883. Relatos cortos: La Grève dernière, Lyon, s.n., 1881; Le Gars Yvon, légende bretonne, París, Imprimerie Adolphe Reiff, 1882. Cuentos y relatos infantiles: Le Livre du jour de l'An, historiettes, contes et légendes pour les enfants, París, Librairie de l'enfance et de l'adolescence J. Brare, 1872; Contes et légendes, París, Kéva, 1884; Légendes et chansons de gestes canaques, 1885, habiendo editado una primera versión en 1875, en folletín. Su primera obra de teatro, Nadine (sin datos de edición), se estrenó en 1882. También escribió relatos y ensayos sobre la locura, la criminalidad, la experiencia carcelaria, que quedaron inéditos y recientemente se han editado (ver más abajo).

11. Louise MicheL, “Le Coq rouge”, Le Citoyen y L’Égalité (ancien citoyen), desde el 19-10-1882.

12. Louise MiCHEL, À travers la vie, París, s.n., 1894

13. Louise Michel, La Commune, París, s.n., 1898. 
materiales ficcionales: véase la novela La Chasse aux Loups, publicada en folletín en 1891, también del periodo londinense, inadvertida hasta su reedición en $2015^{14}$.

1886-1890 fue un periodo fecundo en lo literario, también en lo político, de modo que ambos mundos se conectan. Paralelamente, la autora participaba activamente de las movilizaciones obreras y libertarias de la capital francesa y protagonizaba numerosas intervenciones en prensa y en conferencias. No en vano, como testimonio de su activismo, y de la colindante persecución política, varias de estas obras habían sido redactadas desde la cárcel, lugar que había frecuentado desde su regreso del destierro en Nueva Caledonia (1880). Les Microbes humains fue escrita en la penitenciaría de Clermont Oise, su lugar de encierro tras el mediático juicio por el supuesto asalto a una panadería durante las movilizaciones de marzo de 1883 en París, en un contexto de fuerte carestía económica. La reclusión duró hasta 1886.

Así, movilizada, la encontramos en junio de 1887, cuando preparaba la segunda parte de sus memorias. "Afortunadamente, estoy resfriada, así que no puedo hablar, lo que me permitirá estar un tiempo sin dar una conferencia”. Deseaba hacerse un lugar en el panorama editorial y además poder vivir de ello. "Pero me gustaría saber si M. Roy, al recibirlas, me dará algo de dinero. Tengo mis dos últimos billetes de 100 francos, uno a finales de febrero, el otro el 15 de marzo, y además, tengo que vivir. Habría terminado hace mucho tiempo si no tuviera que lidiar con todo esto" ${ }^{15}$. Las penurias económicas fueron constantes en su vida.

Es este un pequeño testimonio de lo difícil que le resultó sacar adelante su proyecto escritural, tanto a nivel editorial como económico. Su persona atraía mucho el interés de los medios de comunicación, pero las menos de las veces por razones autorales. Tras el juicio por el asalto a la panadería, la prensa se ocupó fundamentalmente del atentado contra ella por parte de un joven al que después, recuperada de aquella herida de bala en la cabeza, Louise Michel defendió ante los tribunales de justicia, por considerar que era el sistema social injusto el que había inducido aquella agresión. Por aquel entonces, la sospecha de locura la acechaba constantemente, en una operación simbólica cargada de connotaciones genéricas que Michel compartió con otras muchas personalidades políticas femeninas de renombre. La virginidad fue, en su caso, otro de los mitos afines. Antes de refugiarse en Londres (desde 1890 hasta el fin de su vida), escapando de una posible reclusión por motivos de salud mental, Michel se concentró en el ciclo de escritura revolucionario que fue la Trilogía Dentu, concebido primero en seis novelas que, finalmente, se redujeron a la mitad. Los títulos del proyecto original y los enunciados de los capítulos realmente publicados se solapan, permitiendo a Claude Rétat y Stéphane Zékian concluir que la autora sí pudo cumplir con la trama argumental inicialmente pergeñada ${ }^{16}$.

Con respecto a la publicación de sus escritos, la autora enfrentó dos problemas no menores. El primero, el editorial. Louise Michel se vinculó con imprentas

14. Louise MichEL, “La chasse aux loupes”, L'Égalité, Organe de concentration socialiste, del 8 de marzo al 23 de mayo de 1891, reeditado en Louise MiCHEL, La Chasse aux Loups, París, Classiques Garnier, 2015. Otro ejemplo, del periodo 1886-1890: Louise MiCHEL, “L'Abbé Cadet”, L'Insurgé, Organe socialiste révolutionnaire indépendant des Égaux du XIe, París, desde el número 15-3/1-4 hasta el 16-6-1887 (núms. 2 a 7), recuperado en Louise MiCHEL, Trois romans, pp. 607-613.

15. Louise MiCHEL, “Carta de Louise Michel a los Barot (carta 769)”, 24-2-1887, en GAUTHIER (ed.), Je vous écris de ma nuit, p. 510.

16. RÉTAT y ZÉKIAN, “Présentation”, pp. 11-16. 
comerciales y cercanas al movimiento obrero (Dénoc, Fayard, Librairie Socialiste Internationale Achille Le Roy, Éditions Kéva), aunque no fue tarea sencilla. Formó parte, además, de un circuito editorial que se relacionaba intensamente con la práctica de la novela folletinesca y de la impresión de textos de manera seriada, por entregas, normalmente al final de una o varias páginas de los periódicos, de forma que ambos formatos, el del folletín y el de la novela exenta, se retroalimentaban ${ }^{17}$. Dos de las tres novelas de la Trilogía Dentu aparecieron paralelamente de forma escalonada. Le Monde nouveau lo hizo, parcialmente, en L'Idée Ouvrière, de Havre, donde había sido disparada apenas dos meses antes, durante nueve de los cuarenta números en los que apareció esta publicación semanal entre 1887 y $1888^{18}$. El tercer texto de la Trilogía, Le Claque-dents, fue publicado previamente en folletín en $L^{\prime} E_{\text {galité }}{ }^{19}$. Se trataba de un rico universo de publicaciones que ordenaba y facilitaba lecturas para los trabajadores, pero que era también muy precario para algunas y algunos de los autores.

El segundo problema que enfrentó Louise Michel a la hora de publicar sus obras, especialmente los materiales ficcionales, fue el del frecuente rechazo de la crítica $^{20}$. Tramas enrevesadas, caóticas, envueltas en atmósferas ancladas en un romanticismo exacerbado y extemporáneo, muy apegadas a los topos más comunes de la obra de Víctor Hugo, y personajes poco definidos y desarrollados, entre otros, fueron algunos de los comentarios más comunes durante la vida de la autora. Una recepción crítica que, apoyada en las distintas apropiaciones posteriores de la figura histórica de Louise Michel, se perpetuó en el tiempo. La historiografía tampoco le concedió demasiado valor estético ${ }^{21}$. Prueba de todo ello es que pocas de sus obras se reeditaron hasta hace bien poco, con dos excepciones: la segunda parte de la Trilogía Dentu por dos casas editoriales españolas (Sempere, hacia 1908, y Vértice, en 1928) y, en su idioma original, la edición de la tercera parte de la misma serie por la editorial, también militante, Plasma, en el año $1980^{22}$. Hasta el año 1999, La Commune y Mémoires de Louise Michel habían sido sus dos obras más veces reproducidas, las dos más vinculadas a las apropiaciones simbólicas ya mencionadas.

17. Eva Golluscio DE Montoya, "Folletines libertarios (Argentina-1900)”, Caravelle. Cahiers du Monde Hispanique et Luso-Brésilien, 65 (1995), 81-102, https://doi.org/10.3406/carav.1995.2659; Eduardo Augusto SouZA CunHA, "Editar a revolta: Edição e circulação de impressos anarquistas em Buenos Aires (1890-1905)”, tesis de maestría, Universidade de Sao Paulo, 2018.

18. Louise MiCHEL, “Le Monde Nouveau”, L'Idée ouvrière, Havre, del 17 de marzo al 9 de junio de 1888.

19. Louise MichEL, “Le claquedents”, L'Égalité, Organe de concentration socialiste, del 26 de junio al 5 de agosto de 1889. Nótese la pequeña diferencia en la transcripción del título. También en este periódico, en fechas próximas: “Louise Michel, "Mémoires de Louise Michel, 'volumen second’”, L'Égalité, Organe de concentration socialiste, 1890.

20. RÉTAT y ZÉKIAN, “Présentation”, pp. 563-582, entre otros testimonios.

21. Como ejemplo, Thierry MARICOURT, Histoire de la litterature libertaire en France, París, Albin Michel, 1990.

22. Luisa Michel [sic], El mundo nuevo, traducción de Soledad Gustavo, Valencia, F. Sempere y Cía., [1908]; Luisa MicheL [sic], El mundo nuevo, traducción de Soledad GuSTAVo, Barcelona, Vértice, 1928; Louise Michel, Le Claque-Dent, París, Plasma, 1980. 
En las dos últimas décadas, sin embargo, esta recepción se ha visto alterada ${ }^{23}$. Las obras de Louise Michel han adquirido valor literario en gran parte gracias al trabajo de recuperación que han hecho una serie de escritoras y estudiosas, fundamentalmente mujeres, apoyadas en una serie de editoriales académicas. La colección "Louise Michel: Euvres”, de la editorial Presses Universitaires de Lyon, artífice de la única reedición completa de la Trilogía Dentu, es un buen ejemplo de ello. Xavière Gauthière, Claude Rétat y Véronique Fau-Vincenti son algunas de ellas ${ }^{24}$. Estas autoras remarcan el valor de la "escritura propia" ya reivindicada en vida por la propia Louise Michel. Recomponen detalladamente el rico universo paratextual de la obra micheliana. Rescatan el valor estético del conjunto ecléctico de sus influencias. Esto último se puede resumir también en un párrafo elocuente de Sidonie Verhaeghe:

Ses textes sont imprégnés par le lyrisme métaphysique de Lamennais et de ses Paroles d'un croyant, qui a marqué ses jeunes années ; et par le romantisme de Victor Hugo, qu'elle admire depuis l'adolescence. Le surnom qu'elle utilise pour signer ses articles et ses poèmes, au moins jusqu'au procès de la Commune, est un hommage : Enjolras, personnage des Misérables. Outre ces premières influences, la littérature de Louise Michel est également empreinte du naturalisme de Zola, duquel elle hérite la volonté de restituer une vision réaliste de la société ; du positivisme de Jules Verne, avec lequel elle partage un intérêt pour les découvertes scientifiques; et du symbolisme des décadents, dans lequel elle voit des similitudes avec le projet social anarchiste ${ }^{25}$.

La labor de recuperación ha sido ingente y muy significativa. Convendría, sin embargo, conectarla, al menos más claramente, con la matriz política de la intervención literaria de Louise Michel. El valor estético micheliano no reside solo en su forma de escritura propia. Remite al universo de la literatura anarquista de la que Michel fue una pluma muy temprana, y después, por distintos motivos, olvidada por el propio movimiento. Sería interesante enlazarlo con los profundos análisis que, sobre esta estética ácrata, iluminó, hace ya cuatro décadas, la historiadora de la literatura Lily Litvak, que todavía siguen dando sus frutos ${ }^{26}$.

El microcosmos imaginado por Louise Michel en su Trilogía Dentu tiene muchos de los elementos frecuentados por aquella retórica: la tipificación de los villanos, movidos por el afán de lucro, que aparece tan claramente en el deforme "hombre de los ojos redondos" de la primera novela, en el gemelo ambicioso de la

23. Los procesos de reedición de la obra de Louise Michel han sido muy bien analizados, paralelamente a los procesos de apropiación simbólica de su figura, por Sidonie VERHAEGHE, "Une anarchiste romantique? Socio- histoire de l'édition des textes de Louise Michel”, COnTEXTES, 30 (2021), https://journals.openedition.org/contextes/9999 (consulta 28-8-2021).

24. Hasta la fecha, la colección "Louise Michel: Euvres”, de la editorial Presses Universitaires de Lyon [en adelante: PUL], Lyon, ha impreso las siguientes obras: Histoire de ma vie (2000); La Livre du bagne, précédé de Lueurs dans l'ombre, plus d'idiots, plus de fous, et du Livre d'Hermann, Lyon, PUL, 2000; Légendes et chansons de gestes canaques (1875), suivi de Légendes et chants de gestes canaques (1885) et de Civilisation, Lyon, PUL, 2001; Louise MiCHEL et Marguerite TinAYRE, La Misère, Lyon, PUL, 2006; Louise MicheL, Trois Romans (2013). También la editorial Garnier, de donde procede Louise MiCHEL, La Chasse aux Loups.

25. VERHAEGHE, “Une anarchiste romantique?”.

26. Lily LiTVAK, Musa libertaria. Arte, literatura y vida cultural del anarquismo español (1880-1913), Madrid, Fundación Anselmo Lorenzo, 2001 [1981]. Sobre la literatura francesa, destacan las aportaciones de Vittorio FrigERIO, donde no hay, por otro lado, alusiones a la obra micheliana: La Littérature de l'anarchisme: Anarchistes de lettres et lettrés face à l'anarchisme, Grenoble, UGA Éditions, 2014; ídem, Nouvelles anarchistes: La création littéraire dans le presse militante (1890-1946), Grenoble, UGA Éditions, 2012, https://doi.org/10.4000/books.ugaeditions.9104. 
segunda, en el barón Eléazar de la tercera y en esa mujer que, bajo distintos nombres, recorre toda la inmensa geografía de la Trilogía lucrándose de la venta de los niños y de las niñas arrojados a sus brazos por la miseria. Los lobos en constante persecución de las caperucitas rojas ${ }^{27}$. La miseria, por otro lado, es el contexto en el que se consignan todas las tramas: las tabernas, los burdeles, las cárceles, los lazaretos y muy especialmente, en estas tres obras, los sanatorios mentales donde se realizan experimentos con humanos. La catalepsia, el hipnotismo, la sugestión, la criminología son reflejo del interés por la ciencia (y la pseudociencia), que se convierte en redentora cuando es aplicada por el médico Gaël, otro de los personajes, en beneficio de la colonia anarquista. Los mundos utópicos que los personajes marginados crean en los confines del nuevo mundo, desde donde planean la revolución social y definitiva que acabará con el viejo, anticipan la revolución libertaria. Todo ello es reflejo de una estética ideologizada, por no mencionar el profundo internacionalismo que emana de la narrativa micheliana, que conecta la geografía revolucionaria de Francia con Irlanda, el imperio ruso y, muy especialmente, con los espacios migratorios, los lugares de reclusión y exilio extraeuropeos, y por tanto con la geografía colonial y anticolonial. El semitismo y el antisemitismo es otro de los lugares que aparecen en la novela, siendo este un tema que pronto colocará al movimiento anarquista ante el espejo, Michel incluida, en referencia a la proximidad del caso Dreyfuss ${ }^{28}$. "La escritura anárquica", "el pastiche de géneros", "la incorrección sintáctica y gramatical” están también presentes en la Trilogía, tres de las marcas de agua que Leandro Delgado ha rescatado recientemente para el caso de la literatura anarquista rioplatense en el cambio de siglo y que, por supuesto, fueron muy subrayadas por los censores literarios del momento ${ }^{29}$.

"Toda palabra que fue pronunciada con rabia” contra el sistema político, social y cultural que el movimiento libertario combatía era "obra de la anarquía”. Esta era la función de la literatura ácrata, según Max Nettlau. A ello se aplicó Louise Michel. También a la imaginación de mundos utópicos, aunque el sabio austríaco no dejara constancia de ello ${ }^{30}$. El repertorio literario anarquista era, por supuesto, muy heterogéneo, indisociable de la cultura del momento y, por tanto, no autónomo. Aun así, la Trilogía micheliana se entiende de una forma más completa como un repertorio de intervención política.

\section{La utopía de Louise Michel}

Al final de la primera novela, el personaje de Julius, uno de aquellos microbios humanos que la autora había puesto bajo el microscopio y había observado huyendo y rebelándose, varias veces condenado por un sistema de justicia corrupto y manipulable y finalmente deportado a Australia, había fundado un espacio utópico, en el sentido de no-lugar o de lugar perfecto imaginado, al que se van a unir, ya desde las últimas

27. La presencia de los cuentos clásicos en MiCHEL en RÉTAT y ZÉKiAN, “Présentation” y notas.

28. Yago Mellado LóPEZ, El anarquismo frente al espejo judío, Madrid, Fundación Anselmo Lorenzo, 2017.

29. Leandro DelgAdo, Anarquismo en el novecientos rioplatense: cultura, literatura y escritura, Montevideo, Estuario Editora, 2017. Los entrecomillados son los subtítulos de su cuarto capítulo.

30. Max NetTlau, La bibliographie anarchiste, Bruxelles, Bibliothèque des “Temps Nouveaux”, 1897. No dejó constancia de la Trilogía Dentu en ídem, Esbozo de historia de las utopías, Buenos Aires, Imán, 1934. 
páginas de Les Microbes humains y en la primera mitad de Le Monde nouveau los condenados del planeta. Aquella colonia había sido creada en un lugar indeterminado del Polo Norte, lugar explorado por varios de los protagonistas aventureros y revolucionarios de la primera entrega Dentu. A ese lugar se dirige el médico Gaël, y los personajes que la autora va a ir introduciendo y convirtiendo en parias de ese mismo sistema.

La colonia, descubierta por el villano de la segunda novela, es alcanzada y destruida. Cuando los personajes de la tercera novela se yerguen contra el sistema y desencadenan la huelga general revolucionaria en Francia, los supervivientes de la colonia se unen a la acción que pone fin al viejo mundo, e instalan uno nuevo. En la última página de Le Claque-dents, el proceso se está replicando en el resto de continentes.

La ficción utópica tuvo un papel importante en la propaganda anarquista de finales del siglo XIX y durante el primer tercio del siglo XX. Al menos fue así en el mundo latino. En Francia, varias décadas después de la Trilogía Dentu de Louise Michel, dos plumas centrales del movimiento libertario firmaron obras de este género: Jean Grave y Sébastien Faure ${ }^{31}$. Joseph Déjacque escribió también en francés el que será el antecedente claro de esta literatura, L’humanisphère, aunque el texto apareció en Nueva York, ciudad en la que estaba exiliado ${ }^{32}$. En italiano, Giovanni Rossi teorizó, primero, sobre la vida futura, para después experimentarla en la Colonia Cecilia, dejando reflejo por escrito de ello ${ }^{33}$. En portugués, Avelino Fosco y Neno Vasco, entre otros, escribieron obras de teatro y relatos cortos de ensoñación utópica ${ }^{34}$. En castellano, los libertarios y las libertarias de ambos lados del Atlántico escribieron, tradujeron y editaron un número llamativo de estas obras, incluyendo una de las tres novelas de la Trilogía Dentu de Louise Michel: El mundo nuevo. Juan Serrano y Oteiza, Ricardo Mella, Marià Burgués, Vicente Carreras, María Fernández Ferraz, Ricardo Flores Magón, Albano Rosell, Pierre Quiroule, Alfonso Martínez Rizo o Adrián del Valle las

31. Jean Grave, Les Aventures de Nono, París, [s.n.], 1901; ídem, Terre libre (Les pionniers), París, [s.n.], 1908; Sébastien FAURE, “Mon communisme”. (Le bonheur universel), París, Imp. "La Fraternelle”, 1921.

32. Joseph DÉJACQUE, “L’humanisphère”, Le Libertaire, Nueva York, números de 1858-1859; parcialmente reimpresa en ídem, L’humanisphére, Bruxelles, Bibliothèque des Temps Nouveaux, 1899.

33. Giovanni Rossi, Un comune socialista, Milano, [s.n.], 1878; ídem, Cecilia, comunita anarchica sperimentale. Un episodio d'amore nella Colonia Cecilia, Biblioteca del "Sempre Avanti", Livorno, Tip. Belforte, 1893. La bibliografía sobre esta experiencia es muy rica. Destaco la originalidad de los siguientes trabajos: Laura FERNÁndEZ CORDERO, "Buenos Aires de la utopía”, en Ernesto BoHOSLAVSKY y Marisa GonZÁlez DE OlEAGA (eds.), El hilo rojo. Palabras y prácticas de la utopía en América Latina, Buenos Aires, Paidós, 2009; ídem, Amor y anarquismo. Experiencias pioneras que pensaron y ejercieron la libertad sexual, Buenos Aires, Siglo XXI, 2017.

34. Avelino FosCO, “O Semeador” (c. 1905-1906), reeditado en María Theresa VARGAS (comp.), Antología do teatro anarquista, São Paulo, WMF Martins Fontes, 2009; Neno VAsco, "Os parasitas” (1935), reeditado en Arnoni Prado, Foot Hardman y Claudia LeAl (comps.), Contos anarquistas, São Paulo, Edtora WMF Martins Fontes, 2011. 
escribieron directamente en este idioma ${ }^{35}$. Pierre Quiroule es, probablemente, el autor mencionado que más atención historiográfica ha recibido ${ }^{36}$. En fechas tempranas encontramos también el primer cuento utópico escrito en catalán: “Amoria”, por Josep Llunas i Pujals, en $1896^{37}$.

Anselmo Lorenzo, José Prat, Soledad Gustavo o Diego Abad de Santillán, entre otros, se encargaron de traducir al castellano las novelas utópicas de Jean Grave, Giovanni Rossi, Louise Michel o Sébastien Faure, respectivamente ${ }^{38}$. El traductor o la

35. Juan Serrano y Oteiza, “¡Pensativo!”, en Primer Certamen Socialista, Reus, Centro de Amigos de Reus, 1885, pp. 469-511; Marià BuRGuÉs, “El siglo de oro”, en Segundo Certamen Socialista, Barcelona, La Academia, 1890, pp. 229-237; Ricardo MELlA, “La Nueva Utopía”, en Segundo Certamen Socialista, Barcelona, La Academia, 1890, pp. 201-227; Vicente CARRERAS, “Acraciápolis”, La Revista Blanca, 1 de octubre de 1902, pp. 223-224; María FERNÁNDEZ FERRAZ, El espíritu del río. Novela socialista, San José de Costa Rica, Imprenta Moderna, 1912; Pierre QuIRoule, Sobre la ruta de la anarquía, novela libertaria, Buenos Aires, Fueyo, 1912; ídem, La ciudad anarquista americana, Buenos Aires, La Protesta, 1914; ídem, En la soñada tierra del ideal, Buenos, Aires, Fueyo, 1924; Ricardo FLORES MAGÓN, “El sueño de Pedro” (1912), en la reedición de sus obras completas a cargo de Jacinto BARRERA BASSOlS y colaboradores: ídem, Obras completas. Cuentos. Relatos. Teatro, Volumen 6, México, D.F., Consejo Nacional para la Cultura y las Artes, 2009, pp. 65-68; Albano RosELL, En el país de Macrobia. Narración naturológica, Barcelona, Biblioteca Naturismo, [1928]; Adrián DEL VALLE, Náufragos, Barcelona, Talleres Gráficos Costa, 1925 (era el número 15 de "La Novela Ideal” de La Revista Blanca, 8-11-1925. Tenía 30 páginas, como todas estas novelas, y contó con una segunda versión más desarrollada: Adrián DEL VALlE, Náufragos, Toulouse, Eds. Universo, 1952); Alfonso MARTínEZ RIzO, 1945. El advenimiento del comunismo libertario. Una visión novelesca del porvenir, Valencia, Mañana, 1932; ídem, El amor dentro de 200 años (La vida sexual en el futuro), Valencia, Orto, 1932.

36. Existen análisis puntuales y muy interesantes sobre algunas de estas obras. Algunos (los de Laura Fernández Cordero, Rocío Hernández Arias, Mariano Martín RodríGuez, Luis Gómez Tovar) son mencionados en otras notas de este artículo. Otros estudios interesantes son: Adriana PETRA, “¿Sueñan los anarquistas con mansiones eléctricas? Ciencia y utopía en las ciudades ideales de Pierre Quiroule”, en BOHOSLAVSKY y GONZÁLEZ DE OlEAgA (eds.), El hilo rojo; Javier PANIAGUA, "El anarquismo español: predominio de la acción”, en Luis GÓMEZ TOVAR y Javier PANIAGUA (eds.), Utopías libertarias españolas. Siglos XIX-XX, Madrid, Tuero, 1991, pp. 41-86. Se presta atención a las obras de Pierre QUIROUlE en Rocío HERNÁNDEZ ARIAS, "Pervivencia y evolución de las estrategias narrativas de Utopía en la trilogía utópica de Pierre Quiroule”, en Pablo GUERRA (ed.), Utopía: 500 años, Bogotá, Ediciones Universidad Cooperativa de Colombia, 2016, pp. 167-192; Dante RAMAGLIA, "La utopía civilizatoria en la Argentina del Centenario”, en Andrés ARTURo RoIG, Proceso civilizatorio y ejercicio utópico en nuestra América, San Juan, Universidad Nacional de San Juan, 1995, pp. 217-241; Celia DE ALDAMA ORDÓÑEZ, “Cruce de centenarios: la utopía anarquista de Pierre Quiroule”, Ángulo Recto. Revista de estudios sobre la ciudad como espacio plural, 7 (2015), pp. 31-43; Félix WEINBERG, Dos utopías argentinas de principios de siglo, Buenos Aires, Hachette, 1976; Gisele HefFEs, Utopías urbanas. Geopolíticas del deseo en América Latina, Madrid, Iberoamericana, 2013; Fernando AínSA, "La ciudad anarquista americana (Estudio de una utopía libertaria)", Cahiers du Monde Hispanique et LusoBrésilien, 46 (1986), pp. 65-78.

37. Josep LlunAs i PujAls, “Amoria”, Almanac de La Tramontana, (1896). Jordi MARTí Font, “Amoria (1896) un conte de Josep Llunas i Pujals: La primera mostra de literatura utòpica en català”, L'Avenç, 411 (2015), pp. 36-41. Este texto fue recuperado en castellano y bajo la autoría de Anselmo LORENZO, “Amoria”, La Revista Blanca, 17-1-1926, pp. 1.244-1.246.

38. Jean GrAve, Las aventuras de Nono, trad. de Anselmo LorEnZO, Barcelona, Publicaciones de la Escuela Moderna, segundo libro de lectura, 1907; ídem, Tierra Libre, trad. de Anselmo LORENZO, Barcelona, Publicaciones de la Escuela Moderna, 1908; Giovanni Rossi, Un episodio de amor en la Colonia socialista Cecilia, traducción de José PrAT, Buenos Aires, Biblioteca de la Questione Sociale, 1896; Louise Michel, El mundo nuevo, traducción de Soledad Gustavo, Valencia, F. Sempere y Cía., [1908]; Sébastien FAURE, Mi Comunismo (La Felicidad universal), traducción de Diego ABAD DE SANTILlÁn, Buenos Aires, Editorial La Protesta, 1922 (el dato de la traducción en la correspondencia de Diego ABAD DE SANTILLÁn con el grupo editorial, Archivo de Diego Abad de Santillán, INSTITUTO INTERNACIONAL DE HISTORIA SOCIAL, Ámsterdam; en adelante, IIHS). 
traductora de El humanisferio, que también se editó en español, se desconoce ${ }^{39}$. Grupos del propio movimiento las imprimieron, al tiempo que dieron curso a otros autores que consideraban cercanos y cuyas novelas concebían como recomendables y necesarias para los trabajadores. En este último caso se encontraría Noticias de ninguna parte, de William Morris, que había sido traducida por el socialista español Juan José Morato en 1903 para la editorial Maucci, desde donde fue varias veces difundida en forma de fascículos, hasta que fue impresa como libro exento en la editorial La Protesta de Buenos Aires en $1928^{40}$.

Aunque es más difícil de mesurar, las anarquistas y los anarquistas leyeron novelas utópicas, porque las reeditaron en varias ocasiones, las comentaron y las volvieron a comentar. Las glosas aparecieron en prólogos y numerosísimos artículos de revistas. Versaron sobre las utopías que ellos denominaron antiautoritarias, las suyas, y sobre las autoritarias, las de los otros, que también leyeron y distribuyeron, aunque en general no editaron (por ejemplo, las obras de Edward Bellamy o H. G. Wells). En muy pocas ocasiones, sin embargo, se mencionaron los textos de Louise Michel como utopías libertarias; se compendiaron junto con otros textos de esta temática o simplemente se glosaron.

Las novelas mencionadas son muy heterogéneas, tanto en su forma como en su contenido. Sin embargo, todas responden a una intención propagandística de ideología libertaria. También la Trilogía de Louise Michel.

La literatura era parte de la revolución por la cultura anarquista y tomar la pluma era una forma de movilización, de acción directa, de ahí que involucrase a primeras figuras, aunque no solo. La literatura utópica, en esencia, así lo pretendía. Encontramos este corpus frecuentemente calificado como ejemplo de propaganda por el hecho, "clamor de un esclavo rebelde", "acero forjado en $8^{\circ}$ y cargado con fulminato de ideas", un conjunto muy especial de escritura destinado a dinamitar los cerebros ${ }^{41}$. Los anarquistas desenvolvieron distintas estrategias con las que anticiparon la sociedad futura. Estas políticas, denominadas prefigurativas, se rastrean tanto en la experimentación de nuevas formas de organización social, como las colonias, las escuelas, las colectividades anarquistas, como en el hecho de escribir e imaginar escenarios utópicos que se preveían cercanos ${ }^{42}$. La estética es muy afín al del resto de la narrativa de los y las anarquistas, pero encierra algunas propuestas muy interesantes, como la de Louise Michel.

Heterogéneo en sus formas, el corpus se nutre fundamentalmente de relatos cortos y novelas largas, pero también se compuso en forma de diálogos teatrales, como el de Avelino Fosco, e incluso dio lugar a ciclos de novelas, como la Trilogía Dentu. En lo que hace a la imaginación del topos utópico libertario, la variedad de escenarios es también grande. En general, podemos diferenciar dos espacios: el escapista, que huye del mundo capitalista y sitúa la geografía utópica anarquista en la selva brasileña, en

39. Joseph DÉJACQUE, El humanisferio: utopía anárquica, Buenos Aires, La Protesta, 1927.

40. William MORRIS, Noticias de ninguna parte o una era de reposo. Capítulo para una novela utópica, Buenos Aires, La Protesta, 1928.

41. DÉJACQUE, El humanisferio, p. 12.

42. Peter SeYferth, “Anarchism and Utopia”, en Randall AmSTER, et al. (eds.), Contemporary Anarchist Studies. An Introductory Anthology of Anarchy in the Academy, Londres/NuevaYork, Routledge, 2009, pp. 280-289. 
alguna isla del Pacífico o en el Polo Norte; y el superador del mundo capitalista, que incorpora los avances técnicos del hombre al servicio de sí mismo y en armonía con la Naturaleza. En la propuesta de Louise Michel, se conjugan ambos: la colonia se sitúa en los confines de la Tierra, pero incorpora a la vida de los miles de personas que la habitan los beneficios de la ciencia, que el doctor Gaël ha puesto a funcionar al servicio de la medicina, del transporte marítimo y aéreo, del ingenio de armas químicas que pongan fin al sistema capitalista. La elección de la geografía polar no se condice, sin embargo, con el hecho de que la civilización ideal libertaria se realizara en total armonía con la Naturaleza. En Les Microbes humains, los colonos quieren fundar su utopía

\begin{abstract}
en algún lugar que solo pertenezca a la naturaleza, ya sea en las heladas soledades de los polos o en las profundas selvas de África, en algún lugar agreste donde sólo acudan los valientes, una colonia de hombres que, cansados del mal que se les hace, o asqueados del mal que han hecho, convertirán el instinto de lucha contra la naturaleza, y tal vez den a luz una raza de la que ya no se desviarán los rudimentos de las cosas más bellas: la justicia, la libertad, la ciencia, desde donde iluminarán a la humanidad del mañana ${ }^{43}$.
\end{abstract}

La imaginación utópica de Louise Michel tiene un pie en los nuevos descubrimientos geográficos de finales del siglo XIX (véase las tierras polares) y otro en la geografía transnacional del anarquismo, específicamente en los espacios coloniales, que funcionaron como lugares disciplinadores para las metrópolis capitalistas (véase los que conectan con su propia experiencia de vida: el destierro en Nueva Caledonia).

Desde el punto de vista del desarrollo de las tramas, el corpus utópico anarquista es, de nuevo, multifacético. Mariano Martín Rodríguez ha descrito la utopía como la "materialización estética de una imagen del mundo", que responde al género genuinamente utópico cuando esa trasposición es "perfecta y, por consiguiente, inalterable”, estática y tendiente a la descripción. Así son los mundos imaginados por Sébastien Faure o Pierre Quiroule, entre otros. Pero se convierte en distópica cuando predomina la narración, empujada en el relato por un conflicto que se deriva de la introducción de algún proceso de cambio. Así son las novelas de Alfonso Martínez Rizo, según este mismo autor ${ }^{44}$. Los fragmentos utópicos de El mundo nuevo imaginado por Louise Michel encajan en esta segunda definición. No deja de ser sorprendente que la colonia micheliana se convierta en una nueva Atlántida, destruida y desaparecida, que reemerge para desencadenar la revolución final. Michel está adelantando aquí otro de los lugares comunes de la ficción utópica anarquista: su capacidad perfectiva, fruto de los elementos más espontáneos de esta ideología. Una capacidad perfectiva que canonizará Piotr Kropotkin en sus textos más constructivos, que estaban apareciendo

43. MiCHEL, Trois Romans, p. 207.

44. Mariano MARTín Rodríguez, "La ciudad libertaria del futuro en la distopía El amor dentro de 200 años (1932), de Alfonso Martínez Rizo”, Ángulo Recto, 3 (2), 2011, pp. 151-169, https://doi.org/10.5209/rev_ANRE.2011.v3.n2.37582. Sobre las utopías de MARTínEz RIzO, véase también Rocío HERNÁNDEZ ARIAS, "Preparar la revolución: acciones violentas en la utopía libertaria hispánica”, Babel, 38 (2008), pp. 19-36; ídem, “Técnicas narrativas del utopismo hispánico: El amor dentro de 200 años, de Alfonso Martínez Rizo y La Ciudad anarquista americana, de Pierre Quiroule”, en Patricia BARRERA VELASCO et al. (eds.), Una llama que no cesa. Nuevas líneas de investigación en filología hispánica, Madrid, Sial Pigmalión, 2017; Augusto URIBE, Apuntes para la historia de la ciencia ficción española: Utopías anarquistas españolas. II Alfonso Martínez Rizo, Madrid, Agustín Jaureguízar, 1998. 
paralelamente a la trilogía micheliana en La Revolté de París ${ }^{45}$. Louise Michel incorpora esta idea dentro de una estructura narrativa que es cíclica. "La armonía despierta para todos"; "Estamos ya en el tiempo de la nueva epopeya, y el último de los grandes bardos se acaba de dormir”. Le toca a ella narrar el paso del ciclón ${ }^{46}$.

En varios momentos del siglo XX se ha vuelto la mirada a ese corpus de ficción utópica libertaria. Las más conocidas de estas obras fueron reseñadas por pensadores y pensadoras ácratas que formaron parte de los varios momentos en los que se reflexionó sobre la literatura utópica en conexión con las posibilidades de renovación histórica: el periodo de los regímenes dictatoriales y totalitarios de entreguerras, los años sesenta del anhelado Estado de bienestar y los años finales del socialismo real ${ }^{47}$. Las exégesis utópicas de los militantes libertarios Max Nettlau, María Luisa Berneri o Ángel Cappelletti se corresponden con esos tres momentos, respectivamente ${ }^{48}$. Ninguno de los tres menciona a Louise Michel como narradora de utopías. Actualmente, el mundo del libro está reeditando estas utopías anarquistas, en parte, aunque no solo, gracias a la labor de pequeñas empresas libertarias y autogestionadas (véase Descontrol o Piedra Papel Libros, pero también Pepitas de Calabaza) ${ }^{49}$. Se trata, quizá, de la reacción de un pequeño sector editorial que propone lecturas alternativas a los productos culturales distópicos que, a fuerza de imaginar futuros peores, han venido reforzando el sistema neoliberal en las tres últimas décadas. La Trilogía Dentu de Louise Michel no aparece aquí. Su reedición en francés, en el año 2013, tampoco aborda los aspectos políticos prefigurativos de las tres novelas.

Existe una novela gráfica muy conocida, titulada La Virgen Roja, escrita y dibujada por Mary y Bryan Talbot, respectivamente, que juega mucho con la idea de Louise Michel como figura afín a la ensoñación utópica. En ella, Charlotte Perkins Gilman, la utopista y seguidora del movimiento nacionalista en Estados Unidos, forjado tras la aparición de El año 2000, de Edward Bellamy, llega a París en el momento en el que tiene lugar el multitudinario entierro de la protagonista. En sus conversaciones con

45. Piotr Kropotkin, La conquête du pain, París, Stock, 1892. Era un compendio de artículos de Le Révolté de Ginebra y París y su sucesora La Révolte (París). Ese mismo año fue reeditado dos veces, en la misma casa. Al año siguiente apareció en Madrid, traducido al castellano. En 1894, se publicó en Buenos Aires.

46. MiCHEL, Trois Romans, pp. 51 y 50.

47. Luis Gómez TOVAR y Almudena Delgado Larios, Utopías libertarias. Esbozo de Historia de las Utopías de Max Nettlau, Madrid, Tuero, 1991.

48. NetTlau, Esbozo de historia de las utopías; María Luisa Berneri, Viaje a través de la utopía, Buenos Aires, Proyección, 1962; Ángel CAPPELlETTI, El pensamiento utópico, siglos XVIII-XIX, Madrid, Tuero, 1990; ídem, El socialismo utópico, Rosario, Grupo Editor de Estudios Sociales, 1968, ídem, Utopías antiguas y modernas, Puebla, Cajica, 1966; ídem, Utopías y antiutopías después de Marx, Montevideo, Recortes, 1997. En los años noventa vieron la luz reediciones y recopilaciones de textos. Véanse las de la Editorial Tuero con el apoyo de la Fundación Salvador Seguí, con sus interesantes trabajos introductorios: Luis GóMEz TOVAR, Ramón GuTIÉRREz y Silvia A. VÁzQUEz (eds.), Utopías libertarias americanas. La ciudad anarquista americana de Pierre Quiroule, Madrid, Tuero, 1991, pp. 397; GÓMEz TOVAR y PANIAGUA (eds.), Utopías libertarias españolas; Luis GómEz TOVAR y Almudena Delgado LARIOS, Utopías libertarias. Esbozo de Historia, Madrid, Tuero, 1991; Joseph DÉJACQUE, El humanisferio. Utopía anárquica, con prólogo de Ángel J. CAPPELLETTI, Madrid, Tuero, 1990.

49. Algunos ejemplos: Ricardo Mella, La nueva utopía, Jaén, Piedra Papel Libros, 2016; Jean GRAVE, Tierra libre, Barcelona, Descontrol, 2016; Jordi M. MARTí FOnT (comp.), Josep Llunes i Pujals. Obra teòrica completa, Barcelona, Descontrol, 2020; Pepitas de Calabaza ha reeditado obras de BELLAMY, MORRIS, KROPOTKIN y MUMFORD, entre otros autores relacionados con este corpus. 
una ex comunera, amiga de Louise Michel, y su hija, que la reciben en la estación, se desarrolla la trama argumental de la novela, que recorre, de manera retrospectiva, la vida de la revolucionaria francesa en dos momentos clave: la Comuna y su destierro en Nueva Caledonia. En varias páginas del cómic encontramos a Louise Michel conjeturando sobre mundos nuevos, donde los inventos mecánicos se han enseñoreado para mostrar los grandes avances técnicos que ella supuestamente imaginaba y proyectaba al servicio de esos lugares mejores. Es especialmente reseñable la conversación que, en esta novela, Perkins Gilman recuerda haber mantenido con Louise Michel en una tarde londinense. Los ecos de la literatura de ciencia ficción, y especialmente de Julio Verne, con quien tantas veces se ha relacionado a Louise Michel, están presentes en este pasaje, y en general, en toda la novela gráfica que, por cierto, ha hecho mucho por difundir la historia de Louise Michel, pues ha sido muchas veces editada y reeditada, en varios idiomas y en grandes tiradas. La imagen que difunde es la de Louise Michel revolucionaria, romántica y abnegada, muy acotada al periodo 18711880 y muy afín a la biografía realizada por Edith Thomas en 1971. No hay ni rastro, sin embargo, de que Louise Michel escribiera sobre esos mundos utópicos que aparecían en su imaginación, ni tampoco, en realidad, de que Louise Michel fuera una escritora de fuerte impronta anarquista ${ }^{50}$.

\section{Las redes transnacionales de edición anarquista y Louise Michel}

En el primer apartado de este artículo hemos abordado el escaso valor estético y político que, en vida y hasta fechas muy recientes, se atribuyó a la fecunda obra literaria de Louise Michel. Esto explica, en parte, esta exclusión. Sin embargo, un análisis más detallado de las redes de propaganda anarquista en perspectiva transnacional nos permite apuntar otros motivos. También arroja luz sobre cómo era aquella densa malla de actividad impresora. En cierto sentido, el corpus de la literatura utópica anarquista fue delimitado por la propia actividad editorial del movimiento en las décadas siguientes a la aparición de la Trilogía Dentu. Si bien las utopías imaginadas por los y las anarquistas emergieron en los años ochenta del siglo XIX (con un precedente lejano, pero muy claro, en El humanisferio de Joseph Déjacque, 1858) y se diseminaron en los siguientes lustros, no es hasta la década de 1920 que fueron objeto de un programa de edición específico, sistemático y de afán completista: la colección "Los Utopistas” de la editorial ácrata La Protesta, de Buenos Aires. Allí se imprimieron los libros de Faure, Déjacque y Morris, al tiempo que se tenía pensado reeditar los de Ricardo Mella y Jean Grave y traducir los textos anticipacionistas de autores tan variopintos como Hans Ryner, Theodor Hertzka y Ernest Coeurderoy, todos ellos mencionados por Max Nettlau en su Esbozo de Historia de las Utopías (1925) ${ }^{51}$. Todos ellos escritos por autores masculinos.

El gran impulsor de la colección "Los Utopistas” de Buenos Aires fue el austríaco Max Nettlau, erudito y Herodoto de la anarquía, que desde Viena se relacionaba intensamente con el grupo editor de La Protesta, en cuyo Suplemento Semanal se publicó originalmente este Esbozo ${ }^{52}$. En realidad, Max Nettlau encontró en

50. Mary M. TALBOT y Bryan TALBOT, La virgen roja, Barcelona, La Cúpula, 2016 (1ª de 2012).

51. Nettlau, Esbozo de historia de las utopías.

52. Max Nettlau, “Esbozo de historia de las utopías”, Suplemento Semanal de La Protesta, Buenos Aires, del 1-7 al 3-8-1925 (números 175-184); Rudolf RocKER, Max Nettlau, el Herodoto de la anarquía, México D.F., Ediciones Estela, 1950. 
el grupo impresor protestista un fácil aliado, pues aquél ya había tenido una relación prolongada, aunque no sistemática, con la edición de utopías ${ }^{53}$. El Suplemento Semanal, después Quincenal, del diario anarquista porteño apoyó esta labor con un aluvión de artículos y reseñas que, con la literatura utópica como eje, estaban firmados por plumas muy reconocibles del panorama libertario internacional ${ }^{54}$. La dictadura militar argentina inaugurada en septiembre de 1930 impidió completar este proyecto editorial.

Aquel corpus de afán completista no incluyó la obra de Louise Michel. Esto fue así a pesar de que una de las tres novelas había sido traducida al castellano y había circulado entre los grupos anarquistas de ambos lados del Atlántico: El mundo nuevo, editada por la casa valenciana Sempere, en torno al año 1908. La había traducido una militante muy conocida por ambos movimientos, Soledad Gustavo, pseudónimo de Teresa Mañé, una de las artífices, junto a su compañero Joan Montseny, de La Revista Blanca en sus dos temporadas, ambas de enorme importancia para la historia del movimiento libertario internacional: Madrid 1898-1905 y Barcelona 1923-1936 ${ }^{55}$. Los motivos de esta traducción y primera edición castellana de El mundo nuevo, al igual que los de la futura exclusión de la colección "Los Utopistas”, se pueden buscar en las redes personales que los libertarios y las libertarias tejieron a través de su activismo transnacional. Estas redes se transformaron, inmediata y posteriormente, en los canales de edición de los materiales libertarios. Generaron continuidades y quiebres que se rastrean muy bien si atendemos a las relaciones interpersonales que las sostenían.

Louise Michel y Soledad Gustavo consolidaron una malla de discusión e intercambio de materiales anarquistas muy fructífera en el cambio de siglo. Se conocieron probablemente en el exilio londinense, aunque resulta difícil precisar los detalles de los primeros encuentros. La densidad del movimiento libertario internacional en la capital británica en este mismo período ha sido muy bien trazada por las investigaciones de Constance Bantman y Pietro di Paola, especialmente para el caso de los expatriados franceses e italianos, respectivamente, aunque la presencia de españoles

53. Habían editado la que posteriormente será la muy difundida obra de Pierre QuIRoule, La ciudad anarquista americana, en 1914. Por cierto, que la siguiente utopía de Pierre QuIROULE, En la soñada tierra del ideal, de 1924, no fue publicada en la colección "Los Utopistas", ni La ciudad anarquista americana reeditada, porque en esos momentos Quiroule y los protestistas se hallaban fuertemente enemistados. En 1921, los protestistas se dieron a la tarea de traducir y editar la recién publicada utopía de Sébastien FAURE, cosa que consiguen inmediatamente (Mi comunismo, 1922). 1922 es una fecha importante para la propaganda protestista. Comienzan a publicar su Suplemento Semanal y el contacto con NeTTLAu se intensifica. En ese contacto, se fragua la colección "Los Utopistas", que era muy ambiciosa, aunque finalmente se materializó solo en dos títulos: DÉJACQUE, El humanisferio y MoRRIS, Noticias de ninguna parte (en 1927 y 1928, respectivamente) y alguna que otra reedición. El Suplemento (véase siguiente nota) profundizó este impulso de literatura utópica anarquista.

54. NetTlau, "Esbozo de historia de las utopías”; Ugo TRENi (pseudónimo de Ugo FeDELI), “Un viaje a las islas de la Utopía”, La Protesta, Buenos Aires, 11-3 y 11, 12, 17, 19, 26-4-1930; Luigi FABBRI, “Cómo haremos la revolución”, La Protesta, Buenos Aires, 10 de diciembre de 1923; ídem, “En los campos siderales de la utopía”, Suplemento Semanal de La Protesta, Buenos Aires, 30 de agosto de 1926; ídem, "El problema del trabajo libre en la anarquía”, Suplemento Quincenal de La Protesta, Buenos Aires, 30 de marzo de 1930; “Bibliografía”, Suplemento Quincenal de La Protesta, Buenos Aires, 31-121928.

55. Dolors MARín, Els Montseny Mañé. Un laboratori de les idees, Reus, Carrutxa, 2010. 
también se subraya en estos relatos ${ }^{56}$. Estos últimos llegaron a Londres durante el período represivo desatado tras la explosión de una bomba entre el público asistente a la procesión del Corpus Christi barcelonés, a la altura de la calle Cambios Nuevos, en junio de 1896. Resonaban, entonces e internacionalmente, los ecos más cruentos del atentado anarquista consignado como acto de propaganda por el hecho. El Gobierno español no dudó en responder con toda su fuerza represora. Cientos de militantes anarquistas fueron encarcelados. Las noticias de las torturas realizadas en la cárcel de Montjuïc y de las durísimas condenas a los militantes anarquistas también traspasaron fronteras y dieron lugar a un proceso de solidaridad internacional de enorme intensidad. Un año después, Michele Angiolillo, anarquista italiano, asesinó al presidente del Gobierno español, Antonio Cánovas del Castillo. En este contexto, llegó Soledad Gustavo a Londres, donde Louise Michel estaba asentada desde 1890.

Apenas dos años después, de nuevo en la Península Ibérica, y durante el primer recorrido de La Revista Blanca, el madrileño que atraviesa el cambio de siglo, Soledad Gustavo tradujo varios artículos de su correligionaria francesa ${ }^{57}$. Es importante subrayar el papel de Teresa Mañé en la propaganda anarquista española e internacional. Traductora, y por tanto, mediadora cultural, fue ella la que volcó al castellano los materiales originales franceses, misma tarea que desempeñó para las casas editoras Sempere y Maucci, funcionando esta relación comercial en diversas direcciones. En primer lugar, el salario recibido por Gustavo fue, en parte, el sostén económico de la familia Mañé-Montseny, y por tanto, de sus proyectos propagandísticos. En segundo lugar, supuso un engranaje muy fructífero para la circulación de libros de propaganda anarquista a través de las casas editoras mencionadas, que tenían interés en difundir títulos de temáticas próximas a las del movimiento, con una capacidad económica que se traducía en tiradas y facilidades de distribución díficiles de alcanzar por aquel, pero cuya propuesta editora también se vio influenciada por mediadores culturales como Teresa Mañé. Es muy probable que ella tuviera cierta capacidad para decidir títulos y animar impresiones ${ }^{58}$. El mundo nuevo, el segundo volumen de la Trilogía Dentu de Louise Michel, no era un libro especialmente difundido. Soledad Gustavo lo conocía de primera mano. Traducirlo y editarlo fue, posiblemente, iniciativa suya.

Un poco antes de aquella traducción, Teresa Mañé había escrito a Louise Michel para solicitarle que enviara una participación directa, de temática antimilitarista, para el

56. Constance BANTMAN, The French Anarchists in London, 1880-1914: exile and transnationalism in the first globalisations, Liverpool, Liverpool University Press, 2013, https://doi.org/10.5949/liverpool/9781846318801.001.0001; Pietro DI PAOLA, The Knights Errant of Anarchy: London and the Italian anarchist diaspora (1880-1917), Liverpool, Liverpool University Press, 2013. Para Louise Michel y Soledad GuSTAVo en el exilio londinense, véase BANTMAN, "Louise Michel's London years” y Dolors MARín, "Prólogo”, en Louise MiCHEL, La comuna de París, Madrid, La Malatesta, 2016.

57. Luisa MicheL [sic], "El gato a la barricada”, La Revista Blanca, Madrid, 1-8-1900, pp. 27-29; Luisa MiCHEL [sic], "El 18 de marzo”, La Revista Blanca, Madrid, 15-6-1901, pp. 30-32. Existe una serie publicada en los números 49 a 56 de La Revista Blanca, Madrid, 1900-1901, titulada "Victor Hugo y Luisa Michel”, escrita por Gustave SIMON.

58. La autobiografía de Joan MONTSENY ofrece buenos testimonios de la relación de la familia Urales con las casas editoriales burguesas catalanas y valencianas; ha sido recientemente reeditada: Mi vida, Barcelona, Universitat de Barcelona, 2020. La tesis doctoral de Ginés PuENTE reconstruye muchos de estos aspectos de la militancia de Soledad Gustavo: "De Soledad Gustavo a Teresa Mañé: los orígenes del anarco feminismo en España (1865-1939)”, tesis doctoral, Universitat de Barcelona, 2021. 
Suplemento y para el Almanaque de La Revista Blanca ${ }^{59}$, pedido al que la francesa respondió ${ }^{60}$. Este canal de colaboración incentivó otras ediciones de la obra de Louise Michel, quien llegó a ser una anarquista muy "estimada y leída en España”. Se tradujeron fragmentos de La Comuna y de Historia de mi vida, los dos textos más exitosos en términos de reediciones en lengua francesa y, como se puede apreciar, también en lengua castellana. Esto último permite subrayar, a su vez, el papel de Soledad Gustavo como mediadora en la circulación de otros materiales de la internacionalista más allá de los más conocidos y canónicos. El anarquista español Fermín Salvochea estuvo detrás de la traducción de algunos de estos fragmentos ${ }^{61}$.

Dolors Marín ha subrayado con acierto que Louise Michel fue una figura muy conocida en España en el cambio de siglo, pero no lo fue tanto en las décadas siguientes $^{62} .1905$ es el año de la muerte de la comunera, pero también el año de cierre de la primera etapa de La Revista Blanca. Hasta 1923, cuando Joan Montseny y Teresa Mañé retornan a la vida a esta publicación, en Barcelona, las menciones en la prensa anarquista de Louise Michel son más bien escasas. Podemos ver aquí una de las explicaciones a la no inclusión de Michel en el corpus de "Los Utopistas". Louise Michel se había cronificado como mito revolucionario, pero su obra no fue especialmente divulgada ${ }^{63}$.

También podemos matizar esta idea. La propia publicación de El mundo nuevo, en torno a 1908, por la editorial Sempere, invita a pensar otros cauces de difusión menos conocidos por la historiografía. Nos devuelven, eso sí, de nuevo, a Soledad Gustavo, quien formó parte de una genealogía muy amplia de mujeres librepensadoras y espiritistas que tuvieron una presencia real y muy fuerte en la movilización urbana de finales del siglo XIX y de la primera década del XX en España. Pensaron la ciudad como un lugar para transformar, en positivo, las profundas fracturas sociales provocadas por la industrialización, y de esta forma conectaron con el pensamiento utópico decimonónico, fundamentalmente el francés de mediados de siglo, pero no $\operatorname{solo}^{64}$. El nuevo mundo de Louise Michel cobra así mayor sentido. Nos instiga, por tanto, a pensar la historia del anarquismo en otros términos, unos que tengan en cuenta la amplitud y variedad temática de la movilización femenina, incluida la edición y divulgación de

59. Teresa MAÑÉ, “Cartas a Louise Michel”, 11 y 23 de agosto y 12 de noviembre de 1904, Fondo Descaves, IIHS, carpeta 301.

60. Luisa Michel (sic), "Muerte a la guerra. A mis amigos de España", Suplemento de La Revista Blanca, Madrid, 1 de septiembre de 1904.

61. Francisco MADRID e Ignacio SORIANO, Antología documental del anarquismo español, en línea, http://www.cedall.org/Documentacio/Castella/cedall203410103.htm (consulta 6 de agosto de 2018), de donde procede lo de “estimada y leída en España”. Louise MiCHEL, La Commune (extracto), traducción de J. Ruipérez, Barcelona, Centro Editorial Presa, [1904]. Este libro forma parte de la importante colección, en términos de propaganda anarquista, “Los pequeños Grandes” Libros, en sus números 14 y 15. Louise Michel, Historia de mi vida, trad. de Fermín SalvocheA, Cádiz, Imp. La Unión, 1905. Solo vieron la luz dos cuadernillos de 16 páginas, a 10 céntimos cada uno.

62. MARÍN, "Prólogo”.

63. Como ejemplos de ese proceso de mitificación: [Soledad Gustavo], "Luisa Michel”, Tierra y Libertad, 19-1-1905. Luisa MicheL [sic], "La nueva Internacional”, Tierra y Libertad, 19 de enero de 1905; Luisa MiCHEL [sic], “La proclamación de la Comuna”, Tierra y Libertad, 19 de enero de 1905.

64. Dolors MARín, Espiritistes i lliurepensadores. Dones pioneres en la lluita pels drets civils, Barcelona, Angle Editorial, 2018. 
materiales utópicos; también, claro que sí, de los menos difundidos: los escritos por otras mujeres ${ }^{65}$.

La suerte posterior de El mundo nuevo, en su edición valenciana, nos impide, todavía, abandonar la figura de Soledad Gustavo como agente cultural y nexo entre el anarquismo francés y el de lengua castellana. Ahondando en su rol de mediación, por último, debemos abordar las características de la versión que hizo de la novela. Esta traducción fue realizada de una forma muy literal y sin un aparato crítico que permitiera contextualizar los personajes, sus lugares de procedencia y deambular o las numerosas referencias a anécdotas, acontecimientos, procesos políticos, mitos, obras literarias y autores, presentes y pasados, que eran constantes en la obra de Louise Michel y en los que Soledad Gustavo apenas interviene, salvo para verter, la mayoría de las veces, los nombres propios al castellano. El resultado fue confuso, más teniendo en cuenta que la traducción estaba operando sobre un recorte específico de la obra, la segunda parte de la Trilogía Dentu, sin que el lector o la lectora pudiera entender las tramas y los personajes conectados a la primera de las novelas, entre otras, la génesis de la colonia libertaria que emerge y se sumerge en El mundo nuevo. El lenguaje y la traducción anarquista también pueden ser objeto de un análisis ideológico. En el cambio de siglo, la traducción libertaria no se concebía como un proceso de acumulación de conocimientos, sino como un acto político, internacionalista, a veces despojado de las normas de ortografía y de corrección lingüística, de forma paralela a lo que sucedía, también en ocasiones, con la escritura. Se necesitan herramientas teóricas que permitan desentrañar estas prácticas alternativas y antijerárquicas, a veces, como en Gustavo, basadas en la "confianza en el lector, para que construya él mismo el significado"66.

La obra de Louise Michel está plagada de vocabulario procedente del argot, del sistema dialectal francés, de neologismos y arcaísmos en uso y en desuso en su época. De ello es testimonio la versión crítica de la Trilogía que han hecho recientemente Claude Rétat y Stéphane Zékian, bien pertrechados de los diccionarios que permiten desenmarañar esta madeja y que, en su día, se sirvieron de la obra micheliana para fundamentar sus estudios sobre la lengua finisecular y sus usos regionales y populares. También han construido un enorme aparato crítico para comprender las referencias de Louise Michel a la historia y a la geografía revolucionaria mundial y a la literatura universal ${ }^{67}$. La edición de 1908 era, sin duda, muy diferente. Quizá podemos encontrar aquí otra explicación de por qué no se glosó en La historia de las utopías de Max Nettlau ni en la colección "Los Utopistas”, de La Protesta, que aquel Esbozo propició.

65. Para pensar nuevas metodologías y fuentes de acceso al estudio del anarcofeminismo, resulta muy interesante Sandra JEPPESEN y Holly NAZAR, "Genders and Sexualities in Anarchist Movement", en Ruth KinNA (ed.), The Bloomsbury Companion to Anarchism, Londres, Bloomsbury, 2014, pp. 162-191. Para profundizar en el análisis de las paradojas y contradicciones organizativas, ideológicas y discursivas del universo anarquista en torno a la emancipación de las mujeres es fundamental FERNÁNDEZ CORDERO, Amor y anarquismo.

66. Resultan interesantes los análisis lingüísticos que Mariana Di STEFANO ha realizado sobre las comunidades discursivas anarquistas: "Políticas del lenguaje del anarquismo argentino (1897-1917)", tesis de doctorado, Universidad de Buenos Aires, 2009. En lo demás, sigo los análisis de Lucía CAMPANELlA, quien, a su vez, retoma la idea de la posible "construcción autónoma del significado” por parte del "lector político" de textos traducidos por anarquistas de Marie-Françoise Melmoux-Montaubin: "La traducción como práctica política: Les 21 jours d'un neurasthénique de Octave Mirbeau en el periódico anarquista Nuevo Rumbo", Mutatis Mutandis. Revista Latinoamericana de Traducción, 14 (2021), pp. 68-91, la cita en p. 88, https://doi.org/10.17533/udea.mut.v14n1a03.

67. Introducción y notas RÉTAT y ZÉKIAN a Louise MiCHEL, Trois Romans. 
Sin embargo, El mundo nuevo de Louise Michel, en la versión de Soledad Gustavo, sí conoció una reedición cercana a esas fechas, la de la Editorial Vértice de Barcelona, en el año 1928. Veamos en qué puntos estas redes editoriales se enlazan y se separan.

La colección "Los Utopistas" conecta sobre todo con las trayectorias de los propagandistas Max Nettlau y Diego Abad de Santillán. Formó parte de un esfuerzo editor con el que se pretendió hacer frente a los muchos desafíos que el anarquismo del período de entreguerras estaba encarando, entre ellos, el reto de que hubieran sido los rusos los primeros en hacer una revolución triunfante. El esfuerzo contempló, como se ha visto, la literatura utópica como una herramienta fundamental de impulso renovador de "la atracción por nuestras ideas"68. Este esfuerzo editor utopista se conjugó con otros, todos ellos de vocación transnacional, con Berlín y París como grandes, aunque no exclusivos, centros intelectuales. Viena y Buenos Aires también contribuyeron ${ }^{69}$. Desde la primera ciudad, Max Nettlau impulsaba algunas de las colecciones. Desde la segunda, los protestistas pudieron capitalizar parte de este esfuerzo editor por varios motivos: contaron con los medios de producción y un amplio público lector; aportaron un mediador cultural que captó, tradujo y prologó muchos de aquellos títulos (Diego Abad de Santillán, del grupo editor, que habitó el Berlín de entreguerras entre 1922 y 1926) y encontraron mermada la otrora gran capacidad editorial de los grupos libertarios españoles, quienes, en plena dictadura de Miguel Primo de Rivera, apenas pudieron dar salida a aquel magma de trasformación ideológica. Desde Barcelona, Joan Montseny y Soledad Gustavo, por ejemplo, se hallaban embarcados en la edición de pequeñas novelas seriadas con las que conseguían vencer los obstáculos de la censura ${ }^{70}$.

Ni Max Nettlau ni Diego Abad de Santillán parecen haber tenido conocimiento de la obra literaria de Louise Michel $^{71}$. Sí que lo tuvieron Hermoso Plaja y Carmen Paredes, impulsores de la Editorial Acracia (Tarragona, desde 1918) y, posteriormente, de la Editorial Vértice (Barcelona, desde 1925), donde se reedita El mundo nuevo en 1928. Vértice fue un proyecto editorial de tipo familiar que consiguió imprimir centenares de títulos a precios muy reducidos. Hasta 1939, en Barcelona; posteriormente, en el exilio mexicano. Tuvo una relación muy estrecha con la impresión de utopías literarias. En la revista Vértice, que portaba el mismo título que la editorial, Hermoso Plaja y Carmen Paredes dieron salida a Memorias de ninguna parte, de William Morris, y Mi comunismo, de Sébastien Faure, ambos en formato folletín. En formato exento, imprimieron La nueva utopía, de Ricardo Mella, y El siglo de oro, de Marià Burgués. También Campos, fábricas y talleres, de Piotr Kropotkin, que, aunque

68. Max NetTlau, “Esbozo de historia de las utopías”, Suplemento Semanal de La Protesta, Buenos Aires, 1 de junio de 1925.

69. En la década de 1920, en Berlín y París, aunque no sólo, se imprimieron, en formato libro, los primeros textos historiográficos del movimiento, a modo de reivindicación crítica de un patrimonio complejo de lucha, y se hicieron contribuciones teóricas innovadoras y clarificadoras (Max Nettlau, Pierre Ramus, Rudolf Rocker, Luigi Fabbri, etc.). También se proyectaron las obras completas de Piotr Kropotkin y Mijaíl Bakunin. La edición de estas obras en castellano se realizó desde Buenos Aires: María MigueláÑEz MARTíneZ, "Editar la anarquía desde el Río de la Plata. Alcances de la cooperación transfronteriza (1890-1939)”, Historia y Política, $42 \quad$ (2019), pp. 85-115, https://doi.org/10.18042/hp.42.04.

70. “La Novela Ideal”, en Federico Urales, “Carta a Diego Abad de Santillán”, 26-5-1925, Archivo Diego Abad de Santillán, IIHS, carpeta 279.

71. En el Archivo de Max NetTlau se conserva correspondencia con Louise MiCHEL y algunos materiales referentes a La Misère. Nada sobre otros escritos: IIHS, Archivo Max Nettlau, carpetas 844, 3.198, 3.642, entre otras. 
no es un material ficcional, fue una obra impulsora principal de este campo de literatura anarquista. Anunciaron, aunque nunca llegó a imprimirse, Les Pacifiques, de Han Ryner. Como se puede apreciar, el recorte de lecturas es muy similar al realizado por la Editorial La Protesta, de Buenos Aires, impulsado por Max Nettlau. En todo, salvo en el hecho de incluir la segunda parte de la Trilogía Dentu de Louise Michel. La proximidad a Barcelona y, por ende, a Soledad Gustavo, de la familia Plaja-Paredes, facilitó el acceso a este material. Su impresión dibuja, por último, un panorama tupido de edición de libros anarquistas en el primer tercio del siglo XX. Estaba fomado por un entramado de conexiones indivuales y grupales, cuyas líneas se encontraron en algunas propuestas y se separaron en otras. El resultado fue, en cualquier caso, sumativo, subrayando el papel de las pequeñas empresas editoras que, como Vértice, restacataron algunos títulos olvidados $^{72}$.

\section{Conclusión}

Los anarquistas y las anarquistas confiaron en la capacidad de la literatura para despertar las pasiones humanas. La historia del libro y de la edición lo es también de los individuos y los grupos que estuvieron detrás, y en la literatura utópica anduvieron algunos muy activos y de una enorme capacidad organizativa. Escribieron, tradujeron, imprimieron y volvieron a editar ficciones de contenido utópico. Louise Michel fue una de ellas. Escribió una Trilogía, publicada por la casa editorial parisina Dentu, entre 1886 y 1890, que comprendida bajo los títulos de Les Microbes humains, Le Monde nouveau y Le Claque-dents, situó el horizonte de expectativas anarquistas en una colonia ubicada en el Polo Norte. Los supervivientes de aquella Atlántida participaron en la revolución social que, en tiempos muy cercanos a los de la autora, ficcionalmente, dio paso a la sociedad libertaria.

Hasta 1939, la literatura anticipacionista, ya fuera en forma de relatos de ficcion, ya en forma de tratados teóricos o planificaciones exhaustivas de la economía postrevolucionaria, ocupó un lugar importante en las labores de difusión, traducción y edición de materiales anarquistas ${ }^{73}$. Derrotada la revolución en España, en el exilio anarquista francés, norafricano y americano, y en los latentes movimientos libertarios de aquellos lugares, desaparecieron ambas modalidades de literatura. La sociedad libertaria se vio, ahora sí, muy lejana. En los últimos años, sin embargo, estos materiales vuelven a los estantes de las librerías. También la Trilogía Dentu, reeditada por la Universidad de Lyon en el año 2013.

En este artículo se han evaluado los motivos por los cuales se deben considerar estas tres obras michelianas dentro del corpus de literatura utópica anarquista. La intención política e ideológica de la autora era evidente. Más si se conecta con una estética libertaria que, desarrollada de forma muy clara en la prensa anarquista del cambio de siglo, en los cuentos, en las imágenes y en un amplio repertorio artístico

72. Ignacio SORIANO JiMÉNEZ, “Hermoso Plaja Saló y Carmen Paredes Sans, el anarquismo silencioso, 1889-1982”, tesis doctoral, Universidad de Salamanca, 2002.

73. En la década de 1930 se observa un cambio en la edición de materiales utópicos anarquistas. La ficción utópica perdió espacio, al tiempo que lo ganaron las propuestas constructivas. La literatura de anticipación libertaria adoptó entonces la forma de los tratados teóricos, no ficcionados, basados, los menos, en el municipio libre y, la mayoría, en el papel rector de los sindicatos en la sociedad futura. Podemos ejemplificar esta labor editorial en las obras de Pierre BESNARD o de Diego ABAD DE SANTILLÁN. 
ácrata, estaba ya presente en Louise Michel, escritora, a finales de la década de 1880. Con posterioridad a esta fecha, las razones de la menor o mayor difusión de estas tres obras no se vinculan, directamente, con las del auge de este campo temático al interior del movimiento anarquista. $\mathrm{O}$, dicho de otra manera, la difusión de este corpus temático se vinculó, por un lado, con el conjunto de apropiaciones simbólicas que los diferentes movimientos sociales hicieron de las figuras de algunos de sus autores y, por otro, con la forma en la que funcionaron las redes de edición anarquista. La cronificación de la figura de Louise Michel como la revolucionaria abnegada y romántica de la Comuna de París de 1871 impidió, por mucho tiempo, fijar la mirada en otros periodos de su vida militante y en otras facetas de su militancia, entre ellas, la propagandista, especialmente a través de la pluma. Una escritura, la de Louise Michel, que fue ideológica, es decir, política.

Este primer elemento influyó en el segundo. En el periodo que recorre el primer cuarto de siglo tras la muerte de Louise Michel, 1905-1930, las escasas reediciones de sus obras literarias se encadenaron a la suerte de individuos y grupos ácratas de habla hispana. Los entramados más sensibles a la obra micheliana fueron los vinculados con las redes femeninas del movimiento librepensador, que tendieron puentes con casas editoriales comerciales como Sempere, y los vinculados con pequeñas editoriales anarquistas, como Vértice, que los cruzaron, sin olvidar la importancia que, dentro de estas mismas redes, tuvo la labor de traducción del francés al castellano, realizada en torno al año 1908 por Soledad Gustavo. Como la escritura, la traducción de obras anarquistas fue un acto político. Como en aquella, la estética libertaria puso más atención en el contenido que en las formas, confiando en la capacidad de los lectores para recomponer los sentidos. Las lecturas de El mundo nuevo imaginado por Louise Michel están mediadas por todas estas posibilidades, sin que resulte fácil trazar una jerarquía. En cualquier caso, su ejercicio de escritura utópica nos devuelve una imagen más compleja de la militante y de la escritora. 